Biospecies Vol. 11 No. 1, January 2018

\title{
Respons Tanaman Jarak Pagar Terhadap Mikoriza Indigenous dan Pupuk P di Lahan Bekas Tambang Batu Bara
}

\author{
Jatropha curcas L. Responses to Indigenous Mycorrhizae and \\ P Fertilizers at Coal Post-Mining Land
}

Elis KARTIKA, LIZAWATI, and HAMZAH

Progam Studi Agroekoteknologi Fakultas Pertanian Universitas Jambi, Kampus Pinang Masak, Mendalo

Darat - Jambi 36361, Telp./Fax: 0741-583051

E-mail: elisk63@yahoo.com

\begin{abstract}
The objective of this research was to assess the response of Jatropha curcas to indigenous Arbuscular Mycorrhizal Fungi (AMF) and P fertilizers applications in former coal mine fields. This study used a single factor Randomized Block Design which is a combination of mycorrhiza and P fertilizer consisting of 10 levels (without FMA and without P fertilizer, without FMA and 25\% recommended doses of P fertilizer, without FMA and 50\% recommended doses of P fertilizer, without FMA and 75\% recommended doses of P fertilizer, without FMA and 100\% recommended doses of P fertilizer, FMA and without P fertilizer, FMA and $25 \%$ recommended doses of $\mathrm{P}$ fertilizer, FMA and 50\% recommended doses of $\mathrm{P}$ fertilizer, FMA and $75 \%$ doses of $\mathrm{P}$ fertilizer, FMA and $100 \%$ recommended doses of $\mathrm{P}$ fertilizer), with recommended doses is $150 \mathrm{Kg}$ SP 36 / ha The observed variables were N, P, K uptake and Jatropha curcas yield. The results showed that the symbiotic of Jatropha curcas with FMA combined with 50\% recommended dose of $\mathrm{P}$ fertilizer gave the best N, P, K uptake and Jatropha curcas yield in Coal Post-Mining Land.
\end{abstract}

Keywords: Arbuscular Mycorrhizal Fungi, Jatropha, coal mine

\begin{abstract}
Abstrak
Tujuan penelitian ini adalah untuk mengkaji respons tanaman jarak pagar terhadap aplikasi Fungi Mikoriza Arbuskular (FMA) indigenous dan pupuk P di lahan bekas tambang batu bara. Penelitian ini menggunakan Rancangan Acak Kelompok satu faktor yaitu kombinasi mikoriza dan pupuk P yang terdiri dari 10 taraf (tanpa FMA dan tanpa pupuk P, tanpa FMA dan 25\% dosis anjuran pupuk P, tanpa FMA dan 50\% dosis anjuran pupuk $\mathrm{P}$, tanpa FMA dan $75 \%$ dosis anjuran pupuk $\mathrm{P}$, tanpa FMA dan $100 \%$ dosis anjuran pupuk $\mathrm{P}$, FMA dan tanpa pupuk P, FMA dan 25\% dosis anjuran pupuk P, FMA dan 50\% dosis anjuran pupuk P, FMA dan $75 \%$ dosis anjuran pupuk $\mathrm{P}$, serrta FMA dan $100 \%$ dosis anjuran pupuk $\mathrm{P}$ ) dengan dosis anjuran $150 \mathrm{Kg}$ SP 36/ha. Peubah yang diamati adalah serapan N,P, K dan hasil tanaman jarak pagar. Hasil penelitian menunjukkan bahwa tanaman jarak pagar yang bersimbiosis dengan FMA yang dikombinasikan dengan 50\% dosis anjuran pupuk $\mathrm{P}$ memberikan serapan N, P, K dan hasil tanaman jarak pagar yang terbaik di lahan bekas tambang batu bara.
\end{abstract}

Kata kunci : FMA, jarak pagar, tambang batu bara

\section{PENDAHULUAN}

Lahan bekas kegiatan tambang batu bara merupakan lahan kritis yang umumnya tidak dapat diusahakan yang disebabkan karena tingkat kesuburan lahan sangat rendah sehingga lahan tersebut menjadi terlantar. Diperlukan berbagai upaya pengendalian yang mengarah pada kegiatan untuk merehabilitasi lahan tersebut, terutama teknologi yang efektif dan praktis tetapi juga lebih murah, dan bersahabat dengan lingkungan.

$$
\text { Alternatif yang mungkin dapat }
$$

dikembangkan untuk mengatasi masalah tersebut 
selain dengan menggunakan bahan tanaman yang toleran (dalam hal ini tanaman jarak pagar), adalah dengan usaha pemanfaatan mikroorganisme bermanfaat seperti mikoriza. Aplikasi mikoriza pada lahan-lahan kritis seperti pada lahan pasca tambang akan sangat bermanfaat, karena di samping dapat mempercepat laju pertumbuhan dan kesehatan bibit di persemaian juga dapat meningkatkan daya hidup dan pertumbuhan tanaman di lapangan. Selain itu penggunaan top soil dan pemupukan kimia juga dapat dikurangi.

Tanaman jarak pagar dapat dipilih untuk mereboisasi lahan bekas kegiatan tambang, karena tanaman ini tidak memerlukan banyak air serta dapat tumbuh di lahan kritis dan tandus. Untuk mengoptimalkan pertumbuhan dan perkembangan tanaman jarak pagar maka perlu aplikasi FMA yang merupakan salah satu alternatif strategi yang mungkin dapat dikembangkan. Akarnya yang kokoh mampu menjadikannya sebagai tanaman konservasi.

Lahan-lahan bekas tambang batu bara tersebut memiliki kondisi tanah kahat unsur hara terutama $\mathrm{N}$ dan $\mathrm{P}$, reaksi tanah masam, top soil tipis, miskin bahan organik dan adanya gejala toksisitas dari Al dan Mn. Hermawan (2011) menyatakan bahwa lahan bekas tambang batubara biasanya memiliki tingkat kepadatan yang tinggi dan kurang subur dikarenakan adanya bahanbahan timbunan yang berasal dari lapisan bawah tanah, baik horizon $\mathrm{C}$ maupun bahan induk tanah.

Berdasarkan pengamatan di lapangan, untuk membantu pertumbuhan dan meningkatkan daya hidup anakan pohon atau tumbuhan pada lahan-lahan marjinal tersebut diperlukan bantuan input energi tinggi dan juga relatif mahal, yakni berupa pengapuran, saturasi fosfat, pemupukan lengkap dan pemberian bahan organik. Dalam rangka pembangunan pertanian yang berwawasan lingkungan perlu dicari alternatif teknologi lain yang tidak saja efektif dan praktis tetapi juga lebih murah, dan bersahabat dengan lingkungan. Aplikasi teknologi mikoriza (dalam hal ini FMA) merupakan salah satu alternatif strategi yang patut dicoba dan dikembangkan di daerah tersebut.

Peranan FMA terhadap pertumbuhan, serapan hara dan hasil tanaman di lahan-lahan kritis sudah banyak dibuktikan. Hasil penelitian Kartika, Duaja, Gusniwati (2016) menunjukkan bahwa aplikasi FMA indigenous dan pupuk kompos mampu meningkatkan pertumbuhan dan produksi tanaman kelapa sawit yang ditanam di lahan ultisols. Suharno dan Sancayaningsi (2013) menyatakan bahwa Fungi Mikoriza Arbuskula mempunyai potensi teknologi mikorizoremediasi logam berat dalam rehabilitasi lahan tambang. Peran mikoriza ini pun telah diketahui mampu meningkatkan kemampuan tumbuhan dalam mempertahankan kemampuan hidup, baik pada habitat yang sesuai maupun habitat lahan-lahan marginal. Pada beberapa dekade belakangan ini kemampuan mikoriza dimanfaatkan dalam remediasi logam berat pada lahan bekas tambang. Kinerjanya menunjukkan bahwa mikoriza mampu menyumbangkan peran kemampuan pertahanan tumbuhan pada lahan marginal. Berbagai jenis FMA juga mampu bersimbiosis dan berperan dalam stabilisasi serta penyerapan logam berat pada lahan tercemar. FMA juga menjadi salah satu alternatif dalam meningkatkan dan 
mengembangkan peran berbagai jenis tumbuhan dalam usaha revegetasi lahan tambang

Percobaan ini bertujuan untuk mengkaji respons tanaman jarak pagar terhadap aplikasi FMA indigenous dan pupuk $\mathrm{P}$ di lahan bekas tambang batu bara.

\section{BAHAN DAN METODE}

Penelitian dilaksanakan di lahan bekas tambang batu bara di desa Madrasah Kecamatan Tengah Ilir Kabupaten Tebo. Penelitian ini menggunakan Rancangan Acak Kelompok satu faktor dengan 3 ulangan yaitu kombinasi mikoriza dan pupuk $\mathrm{P}$ yang terdiri dari 10 taraf (tanpa FMA dan tanpa pupuk P, tanpa FMA dan 25\% dosis anjuran pupuk P, tanpa FMA dan 50\% dosis anjuran pupuk P, tanpa FMA dan $75 \%$ dosis anjuran pupuk P, tanpa FMA dan 100\% dosis anjuran pupuk P, FMA dan tanpa pupuk P, FMA dan 25\% dosis anjuran pupuk P, FMA dan 50\% dosis anjuran pupuk P, FMA dan 75\% dosis anjuran pupuk P, serrta FMA dan 100\% dosis anjuran pupuk $\mathrm{P}$ dengan dosis anjuran $150 \mathrm{Kg} \mathrm{SP}$ $36 /$ ha.

Pembibitan jarak pagar dilakukan pada polybag dan setiap polybag ditanami satu benih. Jumlah inokulan (terdiri atas media tanam, spora, potongan hifa dan potongan akar) diberikan bersamaan dengan penanaman benih. FMA yang diberikan merupakan FMA yang paling efektif hasil percobaan tahun kedua, yaitu isolate Glomus $s p-3$. Pembibitan dipelihara selama 2 bulan. Bibit yang dipindahkan ke lapangan tingginya sekitar $30 \mathrm{~cm}$.
Lahan bekas pertambangan batu bara yang akan ditanami, diratakan dan dibersihkan, kemudian dibuat lubang tanam dengan ukuran 30 $\mathrm{cm} \times 30 \mathrm{~cm} \times 30 \mathrm{~cm}$. Jarak tanam di lapangan adalah $2 \mathrm{~m}$ x $2 \mathrm{~m}$. Selanjutnya dibiarkan selama 2 minggu.

Sebelum ditanami, lubang tanam disisi dengan tanah dan pupuk kandang (5 ton/ha) serta pupuk anorganik (urea, SP 36 dan $\mathrm{KCl}$ ). Bibit dimasukkan ke dalam lubang tanam tersebut, setiap lubang satu bibit. Selanjutnya lubang yang sudah ditanami bibit ditimbun dengan sisa tanah yang ada di permukaan dan tanah dipadatkan.

Pupuk P dalam bentuk SP-36 diberikan pada saat tanam dengan dosis sesuai perlakuan, bersamaan dengan pemberian pupuk urea dan $\mathrm{KCl}$ dengan dosis masing-masing $50 \mathrm{Kg}$ urea/ha (20 g urea/tanaman) dan $50 \mathrm{Kg} \mathrm{KCl/ha} \mathrm{(20} \mathrm{g}$ $\mathrm{KCl} / \operatorname{tanaman}$ ). Pupuk SP 36 dan $\mathrm{KCl}$ diberikan sekaligus saat tanam, sedangkan pupuk urea diberikan bertahap yaitu setengah dosis saat tanam di lapang dan setengah dosis dua bulan kemudian. Selanjutnya dilakukan pemeliharaan tanaman meliputi penyiraman, penyiangan serta pengendalian hama dan penyakit.

Pengamatan dilakukan terhadap peubah serapan $\mathrm{N}, \mathrm{P}, \mathrm{K}$ dan hasil tanaman jarak pagar (jumlah buah per tanaman, jumlah biji per tanaman, bobot kering biji per tanaman). Analisis data dilakukan dengan sidik ragam dan dilanjutkan dengan uji Duncan.

\section{HASIL DAN PEMBAHASAN}

Serapan N, P, K dan hasil tanaman jarak pagar yang ditunjukkan oleh peubah jumlah buah, 
jumlah biji, bobot kering biji per tanaman dapat dilihat pada Tabel 1. Berdasarkan Tabel 1 terlihat bahwa pemberian inokulasi FMA terhadap tanaman jarak pagar (Jatropha curcas L.) pada tanah bekas tambang batu bara dapat meningkatkan seeapan $\mathrm{N}, \mathrm{P}, \mathrm{K}$ dan hasil tanaman tersebut. Hal ini dikarenakan FMA dapat membantu tanaman dalam hal penyerapan air dan unsur hara, jalinan hifa mikoriza yang terbentuk secara intensif akan membantu dan memudahkan tanaman dalam menyerap air dan unsur hara. Kolonisasi mikoriza dapat meningkatkan penyerapan air dan unsur hara. Hasil tersebut sesuai dengan beberapa penelitian yang melaporkan bahwa FMA memiliki kemampuan dalam meningkatkan pertumbuhan, hasil dan penyerapan unsur hara makro terutama fosfat dan beberapa unsur mikro (Ramirez, Mendoza, and Lizaso, 2009; Smith, et al., 2011; Zhang, et al., 2012; Treseder, 2013; Thompson, Clewett, and Fiske, 2013; Habibzadeh, 2015; Lu, et al., 2015).

Tanaman jarak pagar yang diinokulasi FMA memiliki serapan N, P, K dan hasil tanaman yang lebih tinggi dibandingkan dengan tanaman yang tanpa dinokulasi FMA. Hal tersebut disebabkan FMA dengan enzim phosphatasenya mampu membebaskan $\mathrm{P}$ yang tadinya tidak tersedia menjadi tersedia dalam tanah. FMA dapat menyerap fosfat organik dan mengubahnya menjadi $\mathrm{P}$ anorganik yang dapat diserap tanaman dengan adanya bantuan enzim fosfatase asam yang juga dihasilkan oleh FMA dan juga sel-sel tanaman tersebut. Gunawan (1993) menjelaskan bahwa enzim fosfatase asam yang dihasilkan oleh hifa FMA yang sedang aktif tumbuh dan peningkatan aktivitas fosfatase pada permukaan akar sebagai hasil infeksi FMA menyebabkan Pi dibebaskan dari fosfat organik pada daerah dekat permukaan sel sehingga dapat diserap melalui mekanisme serapan hara.

FMA dapat membantu mengatasi masalah ketersediaan fosfat melalui dua cara, pengaruh langsung melalui jalinan hifa eksternal yang di produksinya secara intensif sehingga tanaman bermikoriza akan mampu meningkatkan kapasitasnya dalam menyerap unsur hara dan air (Sieverding, 1991) dan pengaruh tidak langsung, dimana mikoriza dapat memodifikasi fisiologis akar sehingga dapat mengekspresikan asam-asam organik dan fosfatase asam ke dalam tanah (Abbott et al., 1992), dimana menurut Marschner and Dell,(1994); dan Smith and Read, (1997) fosfatase asam merupakan suatu enzim yang dapat memacu proses mineralisasi $\mathrm{P}$ Organik dengan mengatalisis pelepasan $\mathrm{P}$ dari kompleks organik menjadi kompleks anorganik.

Tanaman yang di inokulasi FMA dan dikombinasikan dengan 50\% dosis anjuran pupuk $\mathrm{P}$ memiliki serapan $\mathrm{N}, \mathrm{P}$, dan $\mathrm{K}$ yang tertinggi dibandingkan perlakuan lainnya serta cenderung menunjukkan hasil (jumlah buah per tanaman, jumlah biji per tanaman, bobot kering biji per tanaman).yang lebih tinggi dibandingkan perlakuan lainnya (Tabel 1).

Selanjutnya perlakuan FMA dan 50\% dosis anjuran pupuk $\mathrm{P}$ secara umum memiliki hasil yang tidak berbeda nyata dengan perlakuan tanpa FMA dan 100\% dosis anjuran pupuk P, tetapi dilihat secara ekonomis, tanaman yang di inokulasi FMA dalam hal ini FMA dan 50\% dosis anjuran pupuk $\mathrm{P}$ mampu menghemat penggunaan pupuk anorganik sebesar 50\% dibandingkan 
Tanpa FMA dan $100 \%$ dosis anjuran pupuk P. Dalam hal ini berarti dengan adanya FMA pemakaian pupuk $\mathrm{P}$ menjadi berkurang 50\%, karena dengan FMA dan pemberian 50\% rekomendasi pupuk $\mathrm{P}$ memberikan hasil yang hamper sama dengan tanpa mikoriza dan dikombinasikan dengan $100 \%$ rekomendasi pupuk P.

Tanggap serapan $\mathrm{N}, \mathrm{P}, \mathrm{K}$ terrendah diperoleh pada perlakuan tanpa FMA dan tanpa pemupukan $\mathrm{P}$, sedangkan hasil tanaman jarak pagar terendah diperoleh pada perlakuan tanpa FMA dan 25\% dosis anjuran pupuk $\mathrm{P}$ serta tanpa FMA dan tanpa pupuk P seperti yang ditunjukkan semua peubah yang diamati. Hal ini disebabkan tanaman jarak pagar yang tidak bermikoriza tidak dapat menyerap air dan unsur hara secara optimal sehingga tidak mampu tumbuh dan berkembang dengan baik di lahan bekas tambang batu bara yang memiliki tingkat kesuburan yang sangat rendah, apalagi tanpa atau hanya sedikit penambahan pupuk P. Hasil penelitian Feldere, Jansa, and Schulin (2013) menunjukkan bahwa tanaman Lotus japonicus (L.) yang bermikoriza mampu menyerap unsur hara yang lebih tinggi di berbagai kondisi lingkungan dibandingkan tanaman tanpa mikoriza. Selanjutnya Lu. et al. (2015) menunjukkan bahwa bibit jagung yang di inokulasi FMA memiliki akar yang lebih panjang dibandingkan bibit tanpa FMA sehingga bibit bermikoriza mampu menyerap unsur hara dan tumbuh lebih baik.

Mikoriza memiliki peranan bagi tanaman inangnya, yaitu memperbesar areal serapan bulubulu akar melalui pembentukan miselium di sekeliling akar. Akibat perluasan area jelajah akar melalui bantuan miselium mikoriza sehingga lebih banyak unsur hara yang dapat diserap oleh tanaman inang dibandingkan dengan tanaman lain yang tidak bersimbiosis dengan mikoriza (Laiya et al., 2013)

Simbiosis mikoriza merupakan fenomena yang banyak dijumpai dalam kolonisasi lahanlahan kritis atau miskin hara. Mikoriza dapat menyerap fosfor lebih besar ketika di dalam tanah tingkat ketersediaannya rendah atau terjerap dalam senyawa kompleks. Rendahnya kandungan fosfor pada tanah tambang yang bermikoriza memberikan kontribusi terhadap pertumbuhan tanaman dan ketahanannya dengan penurunan cekaman yang berhubungan dengan ketersediaan hara, kadar garam, logam beracun dan faktor biotik seperti patogen, penyerapan hifa dan bahan organik (Ulfa et al., 2011).

Adanya pertumbuhan hifa eksternal merupakan sumber inokulum penting untuk kelanjutan kolonisasi sistem perakaran yang sama dalam memproduksi spora yang dibentuk dalam tanah yang fungsinya mentransfer hara dari tanah ke tanaman. Hasil penelitian Indriyani et al. (2011) menyatakan bahwa FMA paling berperan dalam meningkatkan serapan $\mathrm{P}$ oleh akar tanaman karena memiliki hifa yang menjalar luas ke dalam tanah melampaui jauh jarak yang dicapai rambut akar. Jamur mikoriza dengan hifa eksternalnya dapat meningkatkan absorpsi dari unsur-unsur yang inmobil di dalam tanah, seperti unsur P, Co, dan $\mathrm{Zn}$ dengan cara menambah atau memperluas absorpsi hara yang diluar kemampuan tanaman tersebut mengabsorpsinya. Rambut akar tanaman yang berasosiasi dengan tanaman yang bermikoriza bisa berkontak dengan volume tanah 
yang lebih luas dan memberikan permukaan absorpsi yang lebih besar dibandingkan pada rambut akar yang tanpa bermikoriza (Indriati et al., 2013).

Adanya hifa eksternal ini penyerapan hara terutama fosfor menjadi besar dibanding dengan tanaman yang tidak terinfeksi dengan mikoriza. Peningkatan serapan fosfor juga disebabkan oleh makin meluasnya daerah penyerapan, dan kemampuan untuk mengeluarkan suatu enzim yang diserap oleh tanaman. 
Tabel 1. Rata-rata serapan N, P dan K tanaman jarak pagar (umur 4 bulan) dan hasil jarak pagar (panen pertama) yang ditanam pada lahan bekas tambang batu bara pada berbagai kombinasi perlakuan FMA dan pupuk $\mathrm{P}$

\begin{tabular}{|c|c|c|c|c|c|c|}
\hline Perlakuan & $\begin{array}{c}\text { Serapan N } \\
(\%)\end{array}$ & Serapan P (\%) & Serapan K (\%) & $\begin{array}{l}\text { Jumlah Buah } \\
\text { per Tanaman }\end{array}$ & $\begin{array}{c}\text { Jumlah Biji per } \\
\text { Tanaman }\end{array}$ & $\begin{array}{l}\text { Berat Biji Kering } \\
\text { per Tanaman }\end{array}$ \\
\hline Tanpa FMA dan tanpa pupuk $\mathrm{P}$ & $1,13 \mathrm{e}$ & $0,21 \mathrm{f}$ & $0,16 \mathrm{c}$ & $4.33 \mathrm{abc}$ & $41.67 \mathrm{ab}$ & $11.53 \mathrm{ab}$ \\
\hline Tanpa FMA dan $25 \%$ dosis anjuran pupuk $\mathrm{P}$ & $1,26 \mathrm{de}$ & $0,32 \mathrm{e}$ & $0,19 \mathrm{c}$ & $1.00 \mathrm{c}$ & $1.00 \mathrm{~b}$ & $0.43 \mathrm{~b}$ \\
\hline Tanpa FMA dan 50\% dosis anjuran pupuk $\mathrm{P}$ & $1,36 \mathrm{~d}$ & $0,48 \mathrm{c}$ & $0,25 \mathrm{c}$ & $11.00 \mathrm{ab}$ & $26.00 \mathrm{ab}$ & $17.57 \mathrm{ab}$ \\
\hline Tanpa FMA dan $75 \%$ dosis anjuran pupuk $\mathrm{P}$ & $1,74 \mathrm{c}$ & $0,54 \mathrm{c}$ & $0,31 \mathrm{c}$ & $1.67 \mathrm{bc}$ & $5.33 \mathrm{~b}$ & $26.98 \mathrm{a}$ \\
\hline Tanpa FMA dan $100 \%$ dosis anjuran pupuk $\mathrm{P}$ & $2,47 \mathrm{~b}$ & $0,68 \mathrm{~b}$ & $1,90 \mathrm{~b}$ & $20.00 \mathrm{a}$ & $50.33 \mathrm{a}$ & $44.97 \mathrm{ab}$ \\
\hline FMA dan tanpa pupuk $\mathrm{P}$ & $1,35 \mathrm{~d}$ & $0,41 \mathrm{~d}$ & $0,22 \mathrm{c}$ & $8.33 \mathrm{abc}$ & $13.00 \mathrm{ab}$ & $6.53 \mathrm{ab}$ \\
\hline FMA dan $25 \%$ dosis anjuran pupuk $\mathrm{P}$ & $1,71 \mathrm{c}$ & $0,63 \mathrm{~b}$ & $0,24 \mathrm{c}$ & $9.67 \mathrm{abc}$ & $29.67 \mathrm{ab}$ & $25.23 \mathrm{ab}$ \\
\hline FMA dan $50 \%$ dosis anjuran pupuk $\mathrm{P}$ & $3,51 \mathrm{a}$ & $0,83 \mathrm{a}$ & $2,18 \mathrm{a}$ & $23.67 \mathrm{a}$ & $63.67 \mathrm{a}$ & $47.93 \mathrm{a}$ \\
\hline FMA dan $75 \%$ dosis anjuran pupuk $\mathrm{P}$ & $2,47 \mathrm{~b}$ & $0,66 \mathrm{~b}$ & $1,96 \mathrm{~b}$ & $14.33 \mathrm{ab}$ & $10.67 \mathrm{ab}$ & $0.97 \mathrm{~b}$ \\
\hline FMA dan $100 \%$ dosis anjuran pupuk $\mathrm{P}$ & $2,39 \mathrm{~b}$ & $0,63 \mathrm{~b}$ & $1,84 \mathrm{~b}$ & $16.33 \mathrm{ab}$ & $22.33 \mathrm{ab}$ & $15.83 \mathrm{ab}$ \\
\hline
\end{tabular}

Keterangan : Angka-angka yang diikuti oleh huruf yang sama pada kolom yang sama menunjukkan berbeda tidak nyata menurut Uji Duncan taraf $\alpha=5 \%$ 


\section{KESIMPULAN}

1. Tanaman jarak pagar yang bersimbiosis dengan FMA menunjukkan hasil lebih tinggi dibandingkan tanaman tanpa inokulasi FMA pada lahan bekas tambang batu bara.

2. FMA yang dikombinasikan dengan $50 \%$ dosis anjuran pupuk $\mathrm{P}$ memberikan serapan N,P, K dan hasil tanaman jarak pagar yang terbaik di lahan bekas tambang batu bara.

3. Tanaman yang bersimbiosis dengan FMA dan ditanam pada lahan bekas tambang batu bara dapat menghemat pemakaian pupuk $\mathrm{P}$ sampai $50 \%$ dari dosis rekomendasi.

\section{DAFTAR PUSTAKA}

Abbott, L. K., A.D. Robson., D. A. Jasper and C. Gazey. 1992. What is the role VA mycorrhizal hyphae in soil . p: $37-41$. Dalam D. J. Read. D.H. Lewis., A. H. Fitter \& I. J. Alexander (penyunting). Mycorrhiza in Ecosytem. CAB. International UK.

Felderer, B., J. Jansa, and R. Schulin. 2013. Interaction between root growth allocation and mycorrhizal fungi in soil with patchy $\mathrm{P}$ distribution. Plant Soil 373:569-582.

Gunawan AW. 1993. Mikoriza arbuskula. PAU Ilmu Hayat. IPB. Bogor.

Habibzadeh, Y. 2015. The effects of arbuscular mycorrhizal fungi and phosphorus levels on dry matter production and root traits in cucumber (Cucumis sativus L,). Academic Journals 9(2) : 65-70.

Hermawan, B. 2011. Peningkatan kualitas lahan bekas tambang melalui revegetasi dan kesesuaiannya sebagai lahan pertanian tanaman pangan. Pros. Seminar asional Budidaya Pertanian. Bengkulu.

Indriati, G., L.I. Ningsih, dan Rizki. 2013. Pengaruh pemberian fungi mikoriza multispora terhadap produksi tanaman jagung
(Zea mays L.). Hal 323-327. Pros. Semirata FMIPA Universitas Lampung.

Indriyani, N.P., Mansyur, I. Susilawati, R.Z. Islami. 2011. Peningkatan produktivitas tanaman pakan melalui pemberian fungi mikoriza arbuskular (FMA). Pastura 1(1):2730.

Kartika, E., Duaja, M.D., dan Gusniwati. 2016. Pertumbuhan Tanaman Kelapa Sawit Belum Menghasilkan (TBM 1) pada Pemberian Mikoriza Indigen dan Dosis Pupuk Organik di Lahan Marjinal. Biospesies 9 (1) : 29-37.

Laiya, R., M.I. Bahua, dan Nurmi. 2013. Pertumbuhan dan produksi jagung hibrida melalui pemberian pupuk hayati. Forum Seminar Prodi S1 Agroteknologi, Jurusan Agroekoteknologi, Fakultas Ilmu Pertanian.

Lu, N., X. Zhou, M. Cui, M. Yu, J. Zhou, Y. Qin, and Y. Li. 2015. Colonization with Arbuscular Mycorrhizal Fungi Promotes the Growth of Morus alba L. Seedlings under Greenhouse Conditions. Forests 6, 734-747.

Marschner, H. \& B. Dell. 1994. Nutrien uptake in mycorrhizal symbiosis. Plant and. Sci. 159: 89-102.

Ramirez, R., B. Mendoza, and J. I. Lizaso. 2009. Mycorrhiza Effect on Maize P Uptake from Phosphate Rock and Superphosphate. Communications in Soil Science and Plant Analysis, 40: 2058-2071

Sieverding . E., 1991. Vesicular-arbuskular mycorrhiza management in tropical indegenous glomales. Deutsche . Jerman. 342 p.

Smith, S. E. dan D. J. Read, 1997. Mycorrhizal Symbiosis. Akademic Press. California USA $35 \mathrm{p}$.

Smith, S.E., I. Jakobsen, M. Grønlund, and F. A. Smith. 2011. Roles of Arbuscular Mycorrhizas in Plant Phosphorus Nutrition: Interactions between Pathways of Phosphorus Uptake in Arbuscular Mycorrhizal Roots Have Important Implications for Understanding and Manipulating Plant Phosphorus Acquisition. Plant Physiology 156 : 1050-1057.

Suharno dan R. P. Sancayaningsih. 2013. Fungi Mikoriza Arbuskula: Potensi teknologi mikorizoremediasi logam berat dalam rehabilitasi lahan tambang. Bioteknologi 10 (1): $37-48$

Thompson, J. P., T. G. Clewett, and M. L. Fiske. 2013. Field inoculation with arbuscular-mycorrhizal fungi overcomes phosphorus and zinc deficiencies of linseed (Linum usitatissimum) in a vertisol subject to 
long-fallow disorder. Plant Soil 371:117137.

Treseder K. K. 2013. The extent of mycorrhizal colonization of roots and its influence on plant growth and phosphorus content. Plant Soil 371:1-13.

Ulfa, M., A. Kurniawan, Sumardi, dan I. Sitepu. 2011. Populasi fungi mikoriza arbuskula (FMA) lokal pada lahan pasca tambang batubara. Jurnal Penelitian Hutan dan Konservasi Alam 8(3): 301-309.

Zhang, T., N. Shi1, D. Bai, Y. Chen4, and G. Feng. 2012. Arbuscular Mycorrhizal Fungi Promote the Growth of Ceratocarpus arenarius (Chenopodiaceae) with No Enhancement of Phosphorus Nutrition. PLOS ONE 7 (9) : 1-8. 